\title{
ESTIMATING SURVIVAL RATES OF UNCATCHABLE ANIMALS: THE MYTH OF HIGH JUVENILE MORTALITY IN REPTILES
}

\author{
David A. Pike, ${ }^{1,3}$ Lígia Pizzatto, ${ }^{1}$ Brian A. Pike, ${ }^{2}$ and Richard Shine ${ }^{1}$ \\ ${ }^{1}$ School of Biological Sciences, University of Sydney, NSW 2006 Australia \\ ${ }^{2}$ Department of Mathematics, University of North Carolina, Chapel Hill, North Carolina 27599 USA
}

\begin{abstract}
Survival rates of juvenile reptiles are critical population parameters but are difficult to obtain through mark-recapture programs because these small, secretive animals are rarely caught. This scarcity has encouraged speculation that survival rates of juveniles are very low, and we test this prediction by estimating juvenile survival rates indirectly. A simple mathematical model calculates the annual juvenile survival rate needed to maintain a stable population size, using published data on adult survival rates, reproductive output, and ages at maturity in 109 reptile populations encompassing 57 species. Counter to prediction, estimated juvenile survival rates were relatively high (on average, only about $13 \%$ less than those of conspecific adults) and highly correlated with adult survival rates. Overall, survival rates during both juvenile and adult life were higher in turtles than in snakes, and higher in snakes than in lizards. As predicted from life history theory, rates of juvenile survival were higher in species that produce large offspring, and higher in viviparous squamates than in oviparous species. Our analyses challenge the widely held belief that juvenile reptiles have low rates of annual survival and suggest instead that sampling problems and the elusive biology of juvenile reptiles have misled researchers in this respect.
\end{abstract}

Key words: juvenile reptiles; lizards; reproductive mode; phylogenetic hypotheses; snakes; Squamata; survival rates; Testudines; turtles.

\section{INTRODUCTION}

Rates of survival of free-living animals are critical determinants of population viability, and hence the measurement of such rates has been a central focus of ecological research (Reed et al. 2003, Frederiksen et al. 2004). A wide variety of methods have been developed to estimate the probability that an individual will survive from one year to the next, including sophisticated statistical modeling (e.g., White and Burnham 1999, Schmidt et al. 2002, Frederiksen et al. 2004). Most of these methods are based on mark-recapture data, and hence rely on the investigator's ability to capture, mark, and most importantly, recapture free-living animals. This requirement creates immense logistical difficulties if some components of the population are difficult to capture, a situation that occurs frequently with the earliest life history stages (Frederiksen et al. 2004). Thus, for example, most mark-recapture studies on reptiles provide little information on the early phases of the life history. This situation reflects the secretive nature of juveniles in many reptile species (Morafka 1994, Pike and Grosse 2006), and due to their small size, our inability to capture them using methods effective for conspecific adults (Ream and Ream 1966, Congdon et al. 1993). Ontogenetic shifts in habitat use (Congdon et al. 1992, Shine and Madsen 1997, Prior et al. 2001)

Manuscript received 31 December 2006; revised 1 June 2007; accepted 30 October 2007. Corresponding Editor: A. Sih.

${ }^{3}$ E-mail: david.pike@bio.usyd.edu.au further exacerbate the problem. To illustrate this phenomenon, Carr $(1952,1967)$ famously referred to the juvenile phase of sea turtle life as "the missing years" because the whereabouts of this life stage, and thus their ecology, is largely unknown. More than five decades later this statement still summarizes the state of our knowledge of most juvenile reptiles in the wild.

The difficulty of finding juvenile reptiles in the field, even in areas where adults can be found quite easily (e.g., Carr 1952, Pike et al. 2005), has suggested to many researchers that these stages are "missing" from the population and hence that juveniles have much lower rates of survival than do conspecific adults (e.g., Morafka 1994, Heppell et al. 1996, Bodie and Semlitsch 2000, Morafka et al. 2000; but see Gibbons 1968). To our knowledge, this speculation has not been tested empirically over a wide range of reptile taxa, for the simple reason that data on juvenile survival are so difficult to obtain.

We suggest a different approach that is independent of our ability to capture juveniles. Instead, we can estimate the probability of an individual's survival through juvenile life from more easily quantified parameters (age at maturation, rates of annual adult survival, and reproductive output) under the simplifying assumption that overall population sizes remain stable through time. That is, if we know the probable duration of a female's reproductive life after she matures, and how many offspring she is likely to produce per annum over that period, we can easily calculate her likely 
lifetime reproductive output (Brommer et al. 2003). If we also know the age at which sexual maturation occurs (i.e., the duration of juvenile life), we can calculate the juvenile survival rate necessary to maintain the population in a stable numerical equilibrium (i.e., where the number of offspring produced, multiplied by their probable survival rate until maturation, is just high enough to balance the rate of adult mortality; Gaillard et al. 1989, Caswell 2001; see also Appendix A). We use these calculated survival rates of juveniles to explore the relationships among basic life history characteristics within the major reptile lineages.

\section{Methods}

We used published reviews plus primary data where necessary (to fill in gaps in the reviews; see Appendix B) to assemble data on the following life history traits for lizards, snakes, and turtles: mean annual survival probability of adult females, mean age at female maturation, mean number of clutches per adult female per year, and mean clutch size. From these data we estimated the mean probability of survival from egg laying (or birth, in viviparous species) to sexual maturation that is needed to achieve a stable population size; and then calculated annual juvenile survival based on that value and the age at maturation (see Appendix A for derivation of our model and Appendix B for our data set). Thus, assuming an equal sex ratio and a stable population we have

$$
2=S_{\mathrm{J}}^{a} \sum_{x=1}^{\infty} n c e^{-M x}
$$

where $S_{\mathrm{J}}$ is the annual juvenile survival rate, $a$ is the age at first reproduction, $x$ is age, $n$ is the number of clutches per year, $c$ is the number in a clutch, and $M$ is the instantaneous adult survival rate. Depending on how one censuses the population we could also have

$$
2=S_{\mathrm{J}}^{a} \sum_{x=1}^{\infty} n c e^{-M(x-1)} .
$$

This is the formula we use in this paper. The above is a geometric series, which can be readily solved:

$$
2=S_{\mathrm{J}}^{a} n c \sum_{x=1}^{\infty} e^{-M(x-1)}=\frac{S_{\mathrm{J}}^{a} n c}{1-S_{\mathrm{A}}}
$$

where $S_{\mathrm{A}}$ is the annual adult survival rate. Rearranging gives

$$
S_{\mathrm{J}}=\sqrt[a]{\frac{2\left(1-S_{\mathrm{A}}\right)}{n c}} .
$$

In cases where data for more than one population of an individual species were available, we used each population as a separate replicate in our analysis (see Harvey and Pagel [1991] for discussion of this approach).

We conducted two types of statistical analyses on our data set: one on raw data, and one that incorporated information on phylogenetic affinities among species. Presumably, survival rates are not genetically coded per se, but factors that plausibly influence survival rates (such as size at hatching) have a strong genetic basis. Thus, phylogenetic conservatism may influence interspecific patterns in juvenile survival rates (Harvey and Pagel 1991). To overcome this problem, we conducted comparative analyses to account for possible phylogenetic constraints (Felsenstein 1985). We investigated the relationships between annual juvenile survivorship and (1) annual adult survivorship, (2) female age at maturity, (3) number of clutches per year, (4) mean clutch size, (5) number of eggs per year, (6) offspring size, (7) female size at maturity, and (8) mode of reproduction (oviparous or viviparous).

For phylogenetic analyses we used independent contrasts with all branch lengths set to one. Relationships among variables were analyzed by linear regressions forced through the origin (i.e., intercepts adjusted to zero; Garland et al. 1992). All contrasts were performed using the PDAP software package (Midford et al. 2005) in Mesquite 1.12 (Maddison and Maddison 2006). Phylogenetic relationships among taxa were obtained from published literature (see Appendix C). In some cases we had to assume that taxonomy was equivalent to phylogeny. Different populations of the same species were considered sister clades (or sometimes polytomies), and we used the supertree technique to solve incongruences among these hypotheses (BinindaEmonds 2004). All tests were run using two phylogenetic hypotheses for the squamates (see Appendix $\mathrm{C}$ for phylogenies), one based mainly on molecular characters (Townsend et al. 2004, Vidal and Hedges 2005) and the other on morphology (Lee 2005).

\section{RESULTS}

We collated life history data on 20 species of lizards (46 populations), 20 species of snakes (40 populations), and 17 species of turtles (23 populations; see data set in Appendix B).

\section{Analyses of raw data}

Differences among taxonomic groups were apparent in both life stages; lizards had the lowest mean annual survival rates, followed by snakes, with turtles having the highest values (juveniles, $F_{2,106}=27.96, P<0.0001$; adults, $F_{2,106}=91.23, P<0.0001$; all Fisher's PLSD (protected least significant difference) post hoc comparisons have $P<0.001$; Fig. 1). Hence, mean annual survival rates differ among lizards, snakes, and turtles in juvenile as well as adult life history stages.

Overall, estimated rates of annual survival were lower for juveniles than for conspecific adults (paired $t=7.39$, $\mathrm{df}=108, P<0.0001$ ), but were not as low as often speculated. Estimated rates of annual survival for juveniles averaged 0.32 for lizards, 0.46 for snakes, and 0.65 for turtles, only $13 \%$ lower (on average) than the measured rates for conspecific adults (Fig. 1). Indeed, 


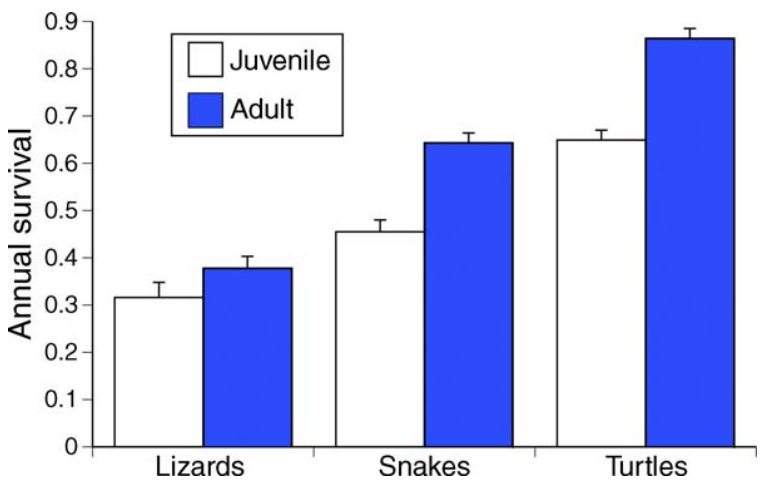

FIG. 1. Annual survival rates (mean $+\mathrm{SE}$ ) for juvenile and adult lizards, snakes, and turtles. Mean values for adults were taken from the literature, and estimates for juveniles were calculated from our model. See Methods for data sources, and the entire Results section for statistical results.

estimated survival rates were actually higher for juveniles than for conspecific adults in 15 lizard species and two turtle species. Strikingly, estimated survival rates were highly correlated across life stages $\left(R^{2}=0.39\right.$, $N=109, P<0.0001 ;$ Fig. 2). That is, species with high rates of annual survival during adult life also have high rates of annual survival during juvenile life (Fig. 2). In addition, juvenile survival rates are strongly related to adult reproductive output $\left(R^{2}=0.16, N=109, P<\right.$ $0.0001)$; higher juvenile survival occurs in species with lower reproductive output. Unsurprisingly, given our methods of calculation, multiple regression suggested that the estimated rate of annual survival of juveniles was related to age at maturation $(t=12.64, P<0.0001)$, number of clutches produced per adult female per year $(t$ $=5.46, P<0.0001)$, and mean clutch size $(t=5.72, P<$ $0.001)$.

More interestingly, juvenile survival rates were significantly correlated with variables independent of those used in our model to estimate those rates. For example, a priori we might predict that the two factors likely to enhance rates of juvenile survival are offspring size (bigger offspring should be more likely to survive) and reproductive mode (viviparity should reduce rates of embryo mortality because it removes the vulnerable egg stage). Our data support both predictions. First, larger offspring had higher survival rates: looking only within squamates (because measures of carapace length in turtles are not equivalent to measures of body length in squamates), species with larger offspring had higher juvenile survival rates $(N=86, r=0.34, P<0.001)$. Body size at hatching or birth was closely tied to body size at maturation for females in our data set $(N=86, r=$ $0.97, P<0.0001$ ), so annual juvenile survival was also significantly linked to mean female size at maturation $(N$ $=86, r=0.27, P<0.02$ ).

Second, comparisons between oviparous and viviparous species (within squamates only, because all turtles are oviparous) also showed the expected patterns.

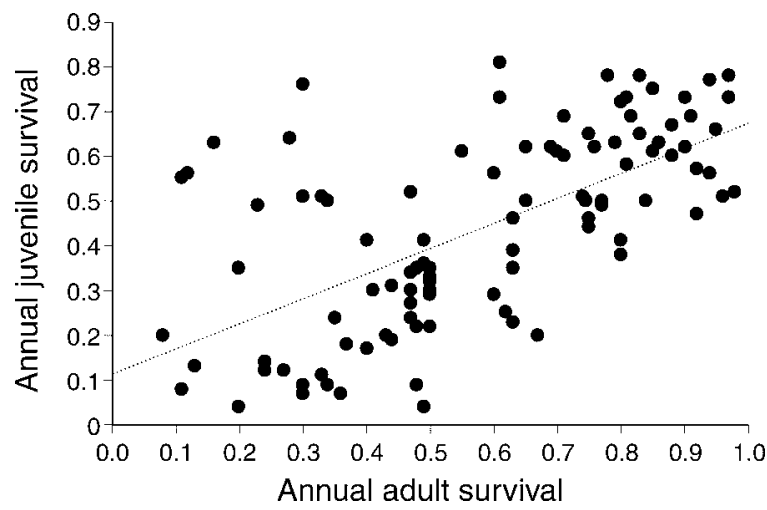

FIG. 2. Relationship between annual juvenile survival rates (calculated from our model) and annual adult survival rates (taken from the literature) for 57 species of lizards, snakes, and turtles (109 populations). Higher annual adult survival rates were correlated with higher annual juvenile survival rates.

Overall, mean annual survival rates of juveniles were higher for viviparous than for oviparous species (means of 0.48 vs. 0.34 ; ANOVA with reproductive mode as the factor, $F_{1,84}=10.72, P<0.002$; Fig. 3). Also, we might expect adult survival rates to play a role in this comparison, because the degree to which viviparity enhances juvenile survival depends upon the pregnant female's probability of surviving long enough to produce a litter. We thus predict that the advantage of viviparity for juvenile survival will be greatest for species with high adult survival rates. To test this prediction, we used analysis of covariance (ANCOVA) with reproductive mode as the factor, adult survival rate as the covariate, and juvenile survival rate as the dependent variable. As predicted, the interaction term was significant (reproductive mode $\times$ adult survival rate, $F_{1,82}=$ $8.75, P<0.004)$; viviparity thus provides less benefit to juvenile survival in taxa with lower rates of adult survival.

\section{Phylogenetically based analysis}

Our comparative analyses revealed many of the same patterns as documented above for analyses based on raw

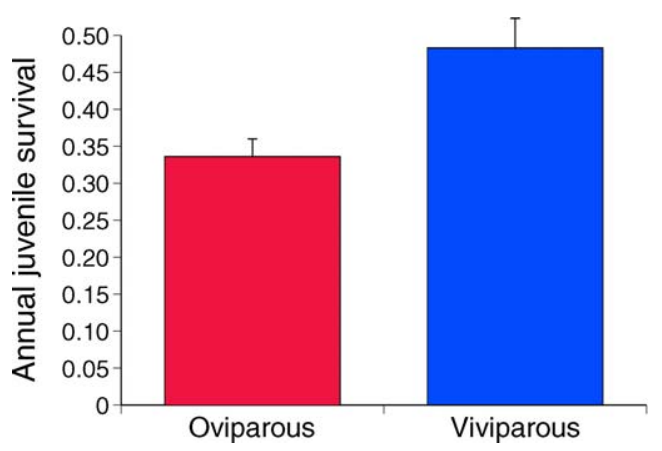

FIG. 3. Annual juvenile survival rates (mean + SE) for oviparous and viviparous squamate reptiles. Oviparous species have lower survival rates than viviparous species. 
data. Thus, evolutionary changes in adult survival rates were consistently accompanied by similar changes in juvenile survival rates (considering both phylogenetic hypotheses, based on Vidal and Hedges (2005), $R^{2}=$ $0.08, P=0.002$; and Lee (2005), $R^{2}=0.09, P=0.002$ ). Annual juvenile survivorship was also correlated with female age at maturity $\left(R^{2}=0.16, P<0.0001\right.$ vs. $R^{2}=$ $0.17, P<0.0001$ ), number of clutches produced per adult female per year $\left(R^{2}=0.05, P=0.01\right.$ vs. $R^{2}=0.05$, $P=0.02)$, but not to clutch size $\left(R^{2}<0.01, P=0.67\right.$ vs. $R^{2}<0.01, P=0.65$ ). Although offspring size was positively correlated with female body size at maturity in phylogenetic comparisons $\left(R^{2}=0.51, P<0.0001\right.$ vs. $R^{2}$ $=0.23, P<0.0001)$, annual juvenile survivorship was not related to offspring size ( $R^{2}=0.02, P=0.23$ vs. $R^{2}<$ $0.01, P=0.39)$ or body size at maturity $\left(R^{2}<0.01, P=\right.$ 0.94 vs. $R^{2}<0.01, P=0.95$ ).

Our independent contrast analysis did not reveal any relationships between mode of reproduction and annual adult survivorship $\left(R^{2}<0.01, P=0.82\right.$ vs. $R^{2}=0.02, P=$ 0.42 ), or between mode of reproduction and annual juvenile survivorship (excluding turtles, $R^{2}=0.01, P=$ 0.53 vs. $R^{2}=0.03, P=0.11$, respectively).

\section{DisCUSSION}

We acknowledge that our analysis is simplistic and imprecise. However, most of the resulting errors (e.g., some populations increasing or decreasing in size rather than being stable through time) should represent random noise, and thus not greatly affect the mean of our estimated rates. Hence, such errors cannot explain the surprisingly high mean survival estimates for juvenile reptiles (Figs. 1, 2). Similarly, random noise should obscure any patterns rather than generate correlations, such as the one we found between the survival rates of adult vs. conspecific juveniles, or between juvenile survival rates and other variables such as offspring size and reproductive mode. Also, the overall positive correlation between survival rates in the two phases of the life history (juvenile vs. adult; Fig. 3) runs directly opposite to the pattern expected as a mathematical artifact: all else being equal, an increase in adult survival should lead the model to calculate a lower juvenile survival rate to maintain stable population numbers. Instead, the positive correlation between survival rates in these two life history phases makes sense in terms of the broad similarity of conspecific juvenile and adult animals, which presumably face similar risks of mortality from predators, diseases, resource fluctuations, and the like (Gibbons 1968, Wilbur 1975, Parker and Brown 1980).

Perhaps our most surprising result is that annual survival rates of juvenile reptiles are relatively high, and similar to those of adult conspecifics (Figs. 1, 2). This conclusion is particularly nonintuitive because our methods of calculation include the egg stage within the juvenile phase, and thus the enormously high rates of egg mortality in many systems (e.g., Burger 1977, Tinkle et al. 1981, Congdon and Gibbons 1990, Burke et al. 1998), which would lead us to expect very low overall survival through to adulthood. The lack of such a pattern, despite high egg mortality in many species, suggests that our calculated rates of juvenile survival are likely underestimates; and hence, that juvenile reptiles may often have survival rates similar to those of conspecific adults.

If survival rates of juvenile reptiles are indeed relatively high, other factors must drive our inability to detect juvenile animals. The primary reason for this may be small body size; smaller animals are harder to see and may be missed in field surveys (Wilbur 1975, Blomberg and Shine 2004). Additionally, juveniles may be sedentary (Sexton 1959, Taylor 1986, Pike and Grosse 2006) or use habitats where they are relatively invulnerable to predators (including humans). Another confounding factor is that juveniles often disperse to new areas; if this is the case then mark-recapture data will tend to underestimate juvenile survival because many surviving offspring move so far from the study area that they are never recaptured, giving the false impression of low survival. In sum, many factors other than low survival may explain low capture rates of juvenile reptiles. We know remarkably little about this critical life stage, and more detailed data are urgently needed.

\section{ACKNOWLEDGMENTS}

We acknowledge the efforts of the many field-workers whose dedication generated the remarkable data sets used in the present analysis. R. Shine thanks T. Madsen for discussion on these topics many years ago. Manuscript preparation was financially supported by an Australian Endeavour International Postgraduate Research Scholarship, a University of Sydney International Postgraduate Award (both to D. A. Pike), and an Australian Research Council Federation Fellowship (to R. Shine).

\section{Literature Cited}

Bininda-Emonds, O. 2004. Phylogenetic supertrees: combining information to reveal the Tree of Life. Computational Biology Series. Volume 4. Kluwer Academic Publishers, Dordrecht, The Netherlands.

Blomberg, S., and R. Shine. 2004. Reptiles. Pages 218-226 in W. Sutherland, editor. Practical census techniques for animal populations. Cambridge University Press, Cambridge, UK.

Bodie, J. R., and R. D. Semlitsch. 2000. Size-specific mortality and natural selection in freshwater turtles. Copeia 2000:732739.

Brommer, J. E., H. Pietiainen, and H. Kolunen. 2003. Natural selection on individual clutch size-laying date trends in the Ural owl. Evolutionary Ecology Research 5:229-237.

Burger, J. 1977. Determinants of hatching success in diamondback terrapin, Malaclemys terrapin. American Midland Naturalist 97:444-464.

Burke, V. J., S. L. Rathbun, J. R. Brodie, and J. W. Gibbons. 1998. Effect of density on predation rate for turtle nests in a complex landscape. Oikos 83:3-11.

Carr, A. 1952. Handbook of turtles: turtles of the United States, Canada, and Baja California. Comstock Publishing Association, Ithaca, New York, USA.

Carr, A. 1967. So excellent a fishe: a natural history of sea turtles. Natural History Press, New York, New York, USA. 
Caswell, H. 2001. Matrix population models. Sinauer Associates, Sunderland, Massachusetts, USA.

Congdon, J. D., A. E. Dunham, and R. C. van Loben Sels. 1993. Delayed sexual maturity and demographics of Blanding's turtles (Emydoidea blandingii): implications for conservation and management of long-lived organisms. Conservation Biology 7:826-833.

Congdon, J. D., and J. W. Gibbons. 1990. The evolution of turtle life histories. Pages 45-54 in J. W. Gibbons, editor. Life history and ecology of the slider turtle. Smithsonian Institution Press, Washington, D.C., USA.

Congdon, J. D., S. W. Gotte, and R. W. McDiarmid. 1992. Ontogenetic changes in habitat use by juvenile turtles, Chelydra serpentina and Chrysemys picta. Canadian Field Naturalist 106:241-248.

Felsenstein, J. 1985. Phylogenies and the comparative method. American Naturalist 125:1-15.

Frederiksen, M., S. Wanless, and M. P. Harris. 2004. Estimating true age-dependence in survival when only adults can be observed: an example with Black-legged Kittiwakes. Animal Biodiversity and Conservation 21:541-548.

Gaillard, J.-M., D. Pontier, D. Allainé, J.-D. Lebreton, J. Trouvilliez, and J. Clobert. 1989. An analysis of demographic tactics in birds and mammals. Oikos 56:59-76.

Garland, T., Jr., P. H. Harvey, and A. R. Ives. 1992. Procedures for the analysis of comparative data using phylogenetically independent contrasts. Systematic Biology 41:18-32.

Gibbons, J. W. 1968. Population structure and survivorship in the painted turtle, Chrysemys picta. Copeia 1968:260-268.

Harvey, P. H., and M. D. Pagel. 1991. The comparative method in evolutionary biology. Oxford University Press, Oxford, UK.

Heppell, S. S., L. B. Crowder, and D. T. Crouse. 1996. Models to evaluate headstarting as a management tool for long-lived turtles. Ecological Applications 6:556-565.

Lee, M. S. Y. 2005. Squamate phylogeny, taxon sampling, and data congruence. Organisms, Diversity and Evolution 4:2545.

Maddison, W. P., and D. R. Maddison. 2006. Mesquite: a modular system for evolutionary analysis. Version 1.12. $\langle$ http://mesquiteproject.org

Midford, P. E., T. Garland, Jr., and W. P. Maddison. 2005. PDAP package of Mesquite. Version 1.07. 〈http:// mesquiteproject.org $\rangle$

Morafka, D. J. 1994. Neonates: missing links in the life histories of North American tortoises. Pages 161-173 in R. B. Bury and D. J. Morafka, editors. Biology of North American tortoises. U.S. Fish and Wildlife Service, Wildlife Research Reports, Washington, D.C., USA.

Morafka, D. J., E. K. Spangenberg, and V. A. Lance. 2000. Neonatology of reptiles. Herpetological Monographs 14: 353-370.
Parker, W. S., and W. S. Brown. 1980. Comparative ecology of two colubrid snakes, Masticophis t. taeniatus and Pituophis melanoleucus deserticola, in northern Utah. Milwaukee Public Museum Publications in Biology and Geology 1:1104.

Pike, D. A., A. Dinsmore, T. Crabill, R. B. Smith, and R. A. Seigel. 2005. Short-term effects of handling and permanently marking gopher tortoises (Gopherus polyphemus) on recapture rates and behavior. Applied Herpetology 2:139-147.

Pike, D. A., and A. Grosse. 2006. Daily activity of immature gopher tortoises (Gopherus polyphemus) with notes on commensal species. Florida Scientist 69:92-98.

Prior, K. A., G. Blouin-Demers, and P. J. Weatherhead. 2001. Sampling biases in demographic analyses of black rat snakes (Elaphe obsoleta). Herpetologica 57:460-469.

Ream, C., and R. Ream. 1966. The influence of sampling methods on the estimation of population structure in painted turtles. American Midland Naturalist 75:325-338.

Reed, D. H., J. J. O'Grady, G. W. Brook, J. D. Ballou, and R. Frankham. 2003. Estimates of minimum viable population sizes for vertebrates and factors influencing those estimates. Biological Conservation 113:23-34.

Schmidt, B. R., M. Schaub, and B. R. Anholt. 2002. Why you should use capture-recapture methods when estimating survival and breeding probabilities: on bias, temporary emigration, overdispersion, and common toads. AmphibiaReptilia 23:375-388.

Sexton, O. J. 1959. Spatial and temporal movements of a population of the painted turtle Chrysemys picta marginata (Agassiz). Ecological Monographs 29:113-140.

Shine, R., and T. Madsen. 1997. Prey abundance and predator reproduction: rats and pythons on a tropical Australian floodplain. Ecology 78:1078-1086.

Taylor, J. A. 1986. Food and foraging behaviour of the lizard, Ctenotus taeniolatus. Australian Journal of Ecology 11:4954.

Tinkle, D. W., J. D. Congdon, and P. C. Rosen. 1981. Nesting frequency and success: implications for the demography of painted turtles. Ecology 62:1426-1432.

Townsend, T., A. Larson, E. Louis, and J. R. Macey. 2004. Molecular phylogenetics of Squamata: the position of snakes, amphisbaenians, and dibamids, and the root of the squamate tree. Systematic Biology 53:735-757.

Vidal, N., and S. B. Hedges. 2005. The phylogeny of squamate reptiles (lizards, snakes, and amphisbaenians) inferred from nine nuclear protein-coding genes. Comptes Rendus Biologies 328:1000-1008.

White, G. C., and K. P. Burnham. 1999. Program MARK: survival estimation from populations of marked animals. Bird Study 46(Supplement):120-138.

Wilbur, H. M. 1975. The evolutionary and mathematical demography of the turtle Chrysemys picta. Ecology 56:64-77.

\section{APPENDIX A}

Details of the model used to estimate annual rates of juvenile survival in lizards, snakes, and turtles (Ecological Archives E089034-A1).

\section{APPENDIX B}

A list of species with associated demographic data used in analysis of juvenile survival rates of lizards, snakes, and turtles (Ecological Archives E089-034-A2).

\section{APPENDIX C} A3).

Phylogenetic hypotheses based on the literature for relationships among the reptile taxa studied (Ecological Archives E089-034- 